\title{
ARD
}

\section{Lymph node IL-18 expression in adult-onset Still's disease}

P Conigliaro, R Priori, M Bombardieri, et al.

Ann Rheum Dis 2009 68: 442-443

doi: 10.1136/ard.2008.093781

Updated information and services can be found at:

http://ard.bmj.com/content/68/3/442.full.html

\section{These include:}

References This article cites 10 articles, 4 of which can be accessed free at: http://ard.bmj.com/content/68/3/442.full.html\#ref-list-1

Email alerting Receive free email alerts when new articles cite this article. Sign up in the service box at the top right corner of the online article.

Notes

To order reprints of this article go to:

http://ard.bmj.com/cgi/reprintform

To subscribe to Annals of the Rheumatic Diseases go to:

http://ard.bmj.com/subscriptions 


\section{Lymph node IL-18 expression in adult-onset Still's disease}

IL-18 is a pleiotropic immunoregulatory cytokine that has been described and implicated in the pathogenesis of a variety of inflammatory diseases. ${ }^{1-4}$

Studies in murine models of arthritis and clinical studies suggest that dendritic cells, macrophages and synoviocites within the synovial membrane can produce IL-18. ${ }^{15-7}$ IL-18 expression has in turn been implicated in the reciprocal regulation of other pro-inflammatory cytokines, such as tumour necrosis factor alpha. ${ }^{8}$

Recent data clearly demonstrated that IL-18 serum levels were significantly elevated in adult-onset Still's disease (AOSD) and correlated with disease activity and serum ferritin levels. ${ }^{2-4}$ AOSD is characterised by substantial and dysregulated cytokine production, with higher levels of IL-18 messenger RNA expression detected in skin and synovial membrane biopsies of active AOSD compared with controls. ${ }^{9}$

However, the main source of IL-18 expression is as yet poorly understood.

We had the opportunity to investigate the expression of IL-18 in two lymph nodes of AOSD and thereby define this site as a critical tissue of origin for IL-18 hyperproduction. The expression was compared with non-specific lymphadenitis (NSL; no systemic inflammatory disorder present) and two lymph nodes from "normal" controls obtained during vascular surgery. Local IL-18 expression was analysed by immunohistochemistry using an IL-18 monoclonal antibody (clone 2D3B6; MD Biosciences, Switzerland) as previously described. ${ }^{10}$ Greater expression of IL18 was observed in AOSD lymph nodes compared with NSL and normal lymph nodes (fig 1). IL-18 was particularly overexpressed in hyperplastic, dysmorphic germinal centres detected in AOSD-derived tissue (fig 1E). Commensurate with our previous observations, IL-18 was also detected in germinal centres of mature follicles in NSL. ${ }^{10}$ Of interest, whereas IL-18 was scarcely detected in the mantle zone in normal lymph nodes (fig 1A), high levels of expression were observed in the mantle zone of AOSD follicles (fig 1E). In addition, numerous
IL18
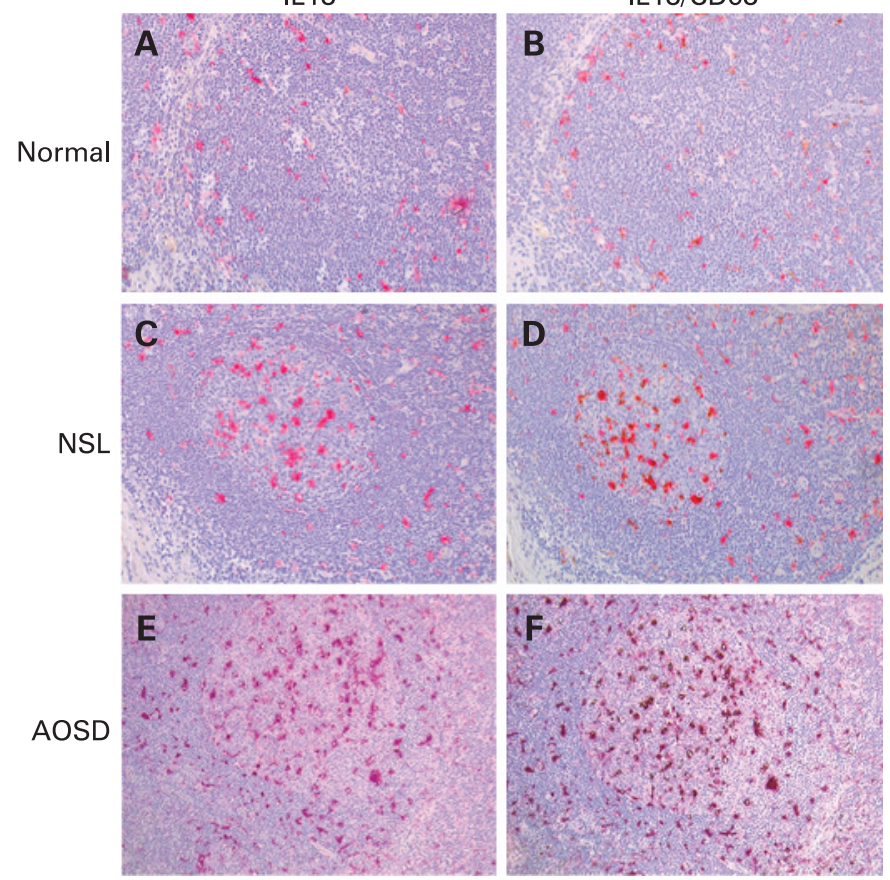

Figure 1 IL-18 immunostaining (purple, left column) and double IL-18 (purple)/CD68 (brown, right column). Immunostaining within lymph nodes in non-reactive $(A, B)$, reactive $(C, D)$ and adult-onset Still's disease (AOSD) (E, F) lymphoid follicles. Original magnification $100 \times$. IL18 expression is massively upregulated within a hyperreactive dysmorphic germinal centre and in the mantle zone of the AOSD lymph node (E). In comparison, a secondary follicle in a normal lymph node shows strong, although lower, expression of IL-18 within the germinal centre and few positive cells in the mantle zone (C). Finally, IL-18 is expressed by scattered cells within a primary follicle (A). In all cases, double immunohistochemistry with CD68 clearly shows co-localisation with CD68-positive cells with dendritic cell/macrophage morphology. NSL, non-specific lymphadenitis.

IL-18-producing cells were observed in afferent lymphatics in biopsies obtained from AOSD and NSL patients compared with normal controls. Finally, we performed double immunohistochemistry for IL-18 and CD68, and found that IL-18 co-localised

Figure 2 Serum levels of IL-18 were measured by ELISA (R\&D Systems, Minneapolis, MN, USA) as previously described. Box-and-whisker plot of IL-18 serum levels in adult-onset Still's disease (AOSD) patients ( $\mathrm{n}=9$ ) (two men, seven women, mean age 28.8 years, range 14-56), primary Sjögren's Syndrome (SjS) patients ( $\mathrm{n}=37$ ), patients with rheumatoid arthritis (RA) $(\mathrm{n}=33)$ and normal controls (NHS) ( $\mathrm{n}=21$ ). Median, quartiles, range and possibly extreme values are shown. ${ }^{*} A O S D$ versus SjS: $p=0.001$; \#AOSD versus RA: $p=0.03$; $\S A 0 S D$ versus NHS: $\mathrm{p}=0.001$.

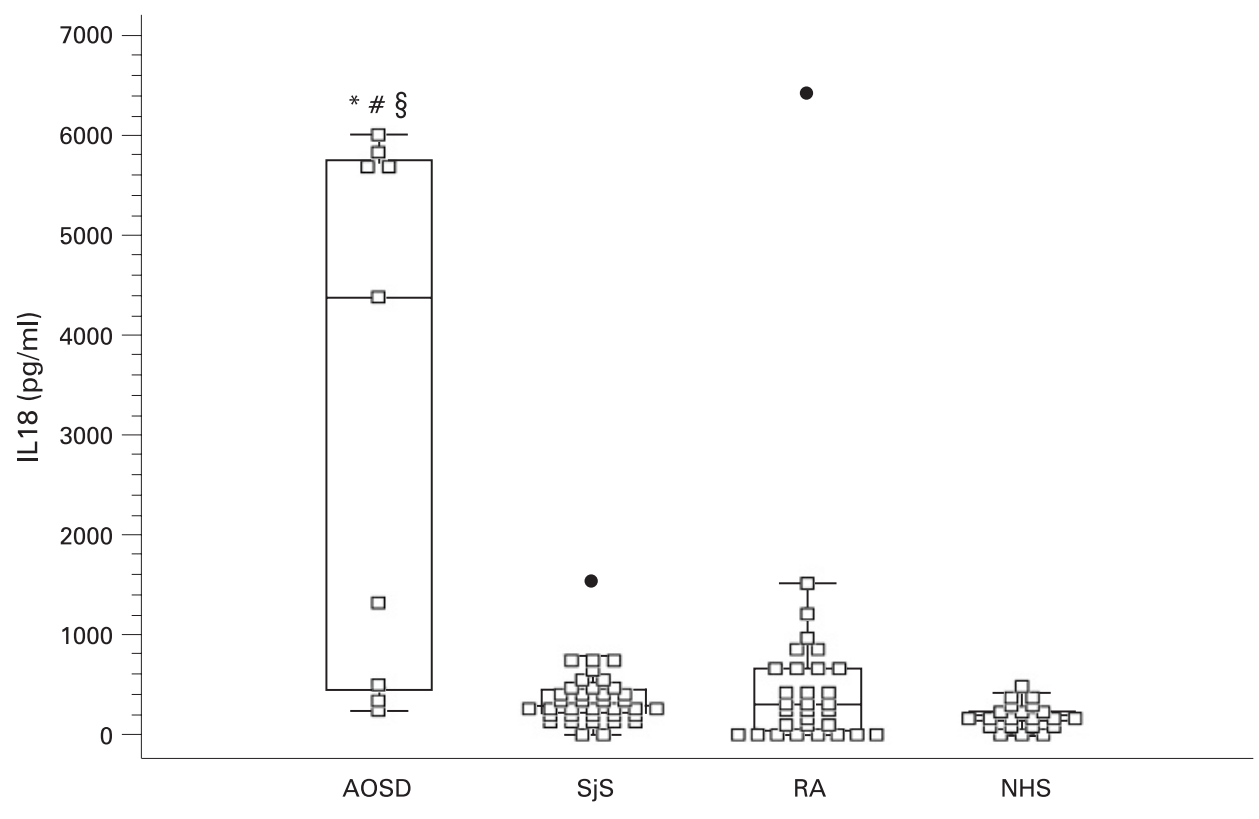


almost exclusively with CD68-positive cells (fig 1F), indicative of a monocyte-macrophage lineage origin in lymph nodes.

We next confirmed increased serum IL-18 levels in nine cases of AOSD compared with patients with rheumatoid arthritis, primary Sjögren's syndrome and healthy subjects, as previously described (fig 2). ${ }^{10}$ Moreover, IL-18 serum levels in AOSD patients correlated with serum ferritin levels (data not shown).

Although the importance of systemic IL-18 upregulation in AOSD is well documented, no data were previously available regarding the nodal expression of IL-18. We provide evidence that IL-18 is highly expressed at the protein level in the germinal centres and in the mantle zone of AOSD lymph nodes compared with non-specific lymphadenitis and "normal" lymph nodes as controls.

The increased systemic production of IL-18, observed in AOSD patients, could reflect the high local expression of this cytokine in the lymph node as an important site for such activation. This observation now needs to be confirmed in larger groups of patients to validate the hypothesis that the lymph node represents a major source of IL-18 in AOSD.

\section{P Conigliaro, ${ }^{1,3}$ R Priori, ${ }^{1}$ M Bombardieri, ${ }^{2}$ C Alessandri, ${ }^{1}$ F Barone, ${ }^{1,2}$ C Pitzalis, ${ }^{2}$ I B Mclnnes, ${ }^{3}$ G Valesini ${ }^{1}$}

${ }^{1}$ Cattedra Di Reumatologia, Dipartimento di Clinica e Terapia Medica, Sapienza Università di Roma, Rome, Italy; ${ }^{2}$ Rheumatology Department, GKT School of Medicine, King's College, London, UK; ${ }^{3}$ Division of Immunology, Infection and Inflammation, University of Glasgow, Glasgow, UK

Correspondence to: Professor G Valesini, Dipartimento di Clinica e Terapia Medica, Cattedra di Reumatologia, Sapienza Università di Roma, V le del Policlinico 155, 00161 Roma, Italy; guido.valesini@uniroma1.it
Funding: PC is receiving fellowship support from the University of Glasgow. MB is receiving support from the Arthritis Research Campaign.

Competing interests: None.

Accepted 22 May 2008

Ann Rheum Dis 2009;68:442-443. doi:10.1136/ard.2008.093781

\section{REFERENCES}

1. Gracie JA, Forsey RJ, Chan WL, Gilmour A, Leung BP, Greer MR, et al. A proinflammatory role for IL-18 in rheumatoid arthritis. J Clin Invest 1999;104:1393-401.

2. Choi JH, Suh CH, Lee YM, Suh YJ, Lee SK, Kim SS, et al. Serum cytokine profiles in patients with adult onset Still's disease. J Rheumatol 2003;30:2422-7.

3. Kawashima M, Yamamura M, Taniai M, Yamauchi H, Tanimoto T, Kurimoto M, et al Levels of interleukin-18 and its binding inhibitors in the blood circulation of patients with adult-onset Still's disease. Arthritis Rheum 2001;44:550-60.

4. Kawaguchi Y, Terajima H, Harigai M, Hara M, Kamatani N. Interleukin-18 as a novel diagnostic marker and indicator of disease severity in adult-onset Still's disease. Arthritis Rheum 2001:44:1716-17.

5. Wei X0, Leung BP, Arthur HM, McInnes IB, Liew FY. Reduced incidence and severity of collagen-induced arthritis in mice lacking IL-18. J Immunol 2001;166:517-21.

6. Plater-Zyberk C, Joosten LA, Helsen MM, Sattonnet-Roche P, Siegfried C, Alouani $S$, et al. Therapeutic effect of neutralizing endogenous IL-18 activity in the collageninduced model of arthritis. J Clin Invest 2001:108:1825-32.

7. Yamamura M, Kawashima M, Taniai M, Yamauchi $\mathrm{H}$, Tanimoto $T$, Kurimoto $\mathbf{M}$, et al Interferon-gamma-inducing activity of interleukin-18 in the joint with rheumatoid arthritis. Arthritis Rheum 2001:44:275-85.

8. Pittoni V, Bombardieri M, Spinelli FR, Scrivo R, Alessandri C, Conti F, et al. Antitumour necrosis factor (TNF) alpha treatment of rheumatoid arthritis (infliximab) selectively down regulates the production of interleukin (IL) 18 but not of IL12 and IL13. Ann Rheum Dis 2002;61:723-5.

9. Chen DY, Lan JL, Lin FJ, Hsieh TY. Proinflammatory cytokine profiles in sera and pathological tissues of patients with active untreated adult onset Still's disease. J Rheumatol 2004;31:2189-98.

10. Bombardieri M, Barone F, Pittoni V, Alessandri C, Conigliaro P, Blades MC, et al. Increased circulating levels and salivary gland expression of interleukin-18 in patients with Sjogren's syndrome: relationship with autoantibody production and lymphoid organization of the periductal inflammatory infiltrate. Arthritis Res Ther 2004;6:R447-56

\section{Axial bone proliferation causing cervical myelopathy in the mutilans form of psoriatic arthritis despite peripheral bone erosion}

The radiographic features of psoriatic arthritis (PsA) can be broadly grouped into destructive and proliferative changes. ${ }^{1}$ Arthritis mutilans, described by Moll and Wright ${ }^{2}$ as "digital telescoping resulting from severe osteolysis" is the most florid form of erosive disease and occurs in less than $5 \%$ of cases. Bony proliferation is also characteristic of PsA and may help differentiate this condition from rheumatoid arthritis. We report a patient with PsA who developed cervical myelopathy as a result of proliferative bony change within the cervical spine, despite extremely severe erosive change at the peripheral joints.

The patient, a 65-year-old man, developed psoriasis at the age of 13 years and arthritis when he was 30 years old. His joint disease was resistant to medical therapy (non-steroidal antiinflammatory drugs, intramuscular gold, sulphasalazine and methotrexate) and continued to progress. $x$ Rays revealed extensive erosive change at the wrists and small joints of the hands and feet, with pencil-in-cup deformities at most of the proximal interphalangeal joints and bone lysis causing $30-50 \%$ resorption of proximal and middle phalanges at all digits of the hands except the left thumb.

He recently presented with numbness and tingling in the hands, exacerbated by coughing and associated with weakness. There was a history of neck stiffness and pain for several years. On examination, upper motor neurone signs were elicited in the upper and lower limbs, with brisk reflexes and upgoing plantar responses, suggesting cervical cord compression. Plain cervical radiography showed no instability at the atlantoaxial joint on flexion and extension views. Magnetic resonance imaging of the cervical spine showed multilevel disc disease, with disc bars and bulging of the ligamentum flavum at $\mathrm{C} 2 / 3$ and $\mathrm{C} 3 / 4$ causing spinal canal stenosis with $\mathrm{T} 2 \mathrm{w}$ hyperintensity at this level indicating myelopathy. Extensive bone proliferation was noted around the odontoid peg and anterior arch of atlas. On multidetector computerised tomography scanning, bony bridging was demonstrated at the atlantoaxial joint and the occipitoatlantal junction (fig 1A,C,D), fixing the base of the skull to the upper spine. 